\title{
Parâmetros qualitativos da carne de cordeiros submetidos aos modelos de produção orgânico e convencional
}

\author{
Qualitative parameters of lamb meat submitted to organic and conventional production \\ models
}

\author{
Nivea Maria Brancacci Lopes ZEOLA ${ }^{1}$; Américo Garcia da SILVA SOBRINHO루 ; Gabriela Milani \\ MANZI ${ }^{1}$
}

${ }^{1}$ Departamento de Zootecnia da Faculdade de Ciências Agrárias e Veterinárias da Universidade Estadual Paulista, Jaboticabal-SP, Brasil

\begin{abstract}
Resumo
Este trabalho objetivou avaliar parâmetros qualitativos da carne, análise sensorial e quantificação de resíduo de droga veterinária e metais pesados provenientes de 48 cordeiros Ile de France submetidos aos modelos de produção orgânico e convencional, os quais foram abatidos aos $32 \mathrm{~kg}$ de peso corporal. A carne dos cordeiros do modelo orgânico teve maior teor de amarelo que a dos cordeiros do modelo convencional aos 45 minutos após o abate, sendo que os demais parâmetros $\mathrm{L}^{\star} \mathrm{e} \mathrm{a}^{\star}$ não foram afetados, já a cor da carne dos cordeiros 24 horas após o abate, não foi influenciada pelos tratamentos. Não houve efeito dos tratamentos no $\mathrm{pH}$ e na temperatura aos 45 minutos e 24 horas após o abate, na capacidade de retenção de água e na força de cisalhamento, enquanto as perdas de peso na cocção foram influenciadas pelos tratamentos. Na carne dos cordeiros criados no modelo orgânico, a maciez subjetiva e a aceitação global foram inferiores quando comparadas às do modelo convencional.Os tratamentos não influenciaram os teores de arsênio, cádmio e chumbo da carne. Constatou-se inexistência do princípio ativo ivermectina na carne proveniente dos modelos de produção orgânico e convencional.
\end{abstract}

Palavras-chave: Capacidade de retenção de água. Cor. Maciez. Metais pesados. Perdas de peso na cocção.

\begin{abstract}
This work aimed to evaluate qualitative parameters of meat, sensorial analysis, ivermecin residue and heavy metals from 48 Ile de France lambs submitted to organic and conventional production models which were slaughtered at $32 \mathrm{~kg}$ of body weight. Lamb meat from organic model had larger yellowness w to compawithto conventional mo to 45 minutes after the slaught anbut $\mathrm{L}^{*}$ and $\mathrm{a}^{\star}$ parameters were not affeced; however, not eady the color of lamb meat 24 hours after the slaugter, not influenced by treatments. There was not effect of treatments in $\mathrm{pH}$ and temperatureat 45 minutes and 24 hours after the slaughter, in water holding capacity and in shear force, while the cooking losses were influenced by treatments. In the meat of lambs submitted to organic model, the subjective tenderness and the global acceptance were lower when compared to convencional model. Treatments didn't influence arsenic, cadmium and lead meat tenor. Inexistence of ivermectin was verified in meat from organic and conventional production models.
\end{abstract}

Keywords: Water holding capacity. Color. Tenderness. Heavy metals. Cooking losses.

\section{Introdução}

Tecnologias de uso sustentável dos recursos produtivos, com preservação e ampliação da biodiversidade, conservação do solo, água e ar são consideradas características de um modelo orgânico de produção de carne, sem uso de insumos artificiais tóxicos, como os agrotóxicos, organismos geneticamente modificados e outras substâncias contaminantes que possam prejudicar a saúde da população e o meio ambiente, primando por técnicas alternativas como a homeopatia no controle sanitário dos animais ${ }^{1}$.
Atualmente a produção orgânica é ainda pequena em relação ao modelo convencional, sendo o Brasil considerado o trigésimo quarto país na exportação de produtos orgânicos. O principal entrave na produção de alimentos orgânicos é a baixa escala de produção, que implica em maiores custos de mão-de-obra e insumos/ unidade

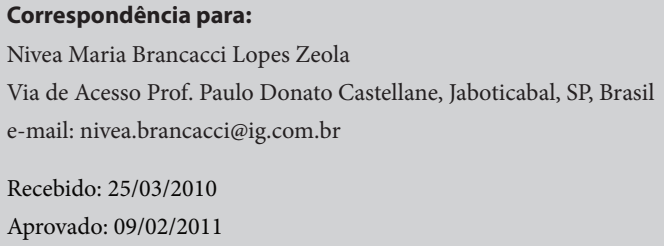


de produto, seguida da falta de recursos e treinamento dos produtores ${ }^{2,3}$. Entretanto o consumidor moderno busca consumir carne obtida humanitariamente, sendo importante que os animais não sofram dor, injúria e estresse durante sua criação e abate, garantindo o bemestar animal ${ }^{4}$. $\mathrm{O}$ abate humanitário consta no anexo da Instrução Normativa do Ministério da Agricultura, Pecuária e Abastecimento ${ }^{5}$, apresentando o conjunto de diretrizes técnicas e científicas que garantem o bem-estar dos animais desde a recepção até a sangria ${ }^{6}$.

No Brasil, a produção de alimentos orgânicos é regulamentada por Instrução Normativa cujos procedimentos disciplinam a produção, tipificação, processamento, envase, distribuição e certificação da qualidade de produtos de orgânicos, biodinâmicos, biológicos e agroecológicos ${ }^{7}$. Há 19 certificadoras habilitadas pelo Ministério da Agricultura para vistoriar, orientar e fiscalizar projetos de conversão, sendo os principais órgãos certificadores a Associação de Agricultura Orgânica (AAO), com selo aceito apenas no mercado nacional e o Instituto Biodinâmico ${ }^{8}$, com seis credenciamentos internacionais, entre eles o da IFOAM (International Federation on Organic Agriculture Movements), permitindo certificação aceita na Europa, nos Estados Unidos e no Japão9.

Resultados experimentais da comparação entre modelos de produção orgânico e convencional são incipientes, notadamente por necessitar de longos períodos de avaliação para sua validação, com abordagens técnicas e econômicas ${ }^{10}$. Em relação à aceitabilidade dos produtos orgânicos, os consumidores descrevem que suas características sensoriais são melhores do que os similares convencionais e tem sido demonstrado que o rótulo associado ao alimento pode criar expectativas positivas em relação às características sensoriais do produto, beneficiando sua aceitabilidade ${ }^{3}$.

A produção animal sustentável utiliza os recursos naturais renováveis a ritmos inferiores do que os da produção contínua. A eficiência biológica deve preservar as características do produto a ser registrado e certificado. No caso da carne, sua qualidade dependerá do crescimento e deposição dos componentes do peso corporal, efeitos residuais da ingestão de alimentos, condições pré e pós-abate, e o mercado consumidor disponível a pagar maiores preços pelo produto ${ }^{11}$.

A segurança alimentar fundamenta-se no controle de remanescentes residuais nos alimentos, em decorrência do uso de pesticidas, drogas veterinárias ou acidentes envolvendo contaminantes ambientais ${ }^{12}$. O MAPA publicou no Diário Oficial da União a Portaria n ${ }^{\circ} 50$, de 3 de março de 2006, que aprovou os Programas de Controle de Resíduos em Carnes, visando garantir controle e monitoramento dos resíduos e contaminantes dos produtos pecuários brasileiros com destino à exportação e ao mercado interno. São preconizadas análises de resíduos de antimicrobianos como antibióticos, de tireostáticos, de pesticidas, de antiparasitários, de anabolizantes, de beta-agonistas e de metais pesados.

Os contaminantes inorgânicos referem-se aos metais pesados ou tóxicos como antimônio, arsênico, cádmio, chumbo, cobre, cromo, estanho, mercúrio, níquel, selênio e zinco, cujos limites de tolerância são estabelecidos. Em carnes, os teores de cádmio variam de 0,19 a 3,49 ppm, sendo que o Comitê de Peritos em Aditivos e Alimentos da Food and Agriculture Organization/Organização Mundial da Saúde (FAO/OMS) estabeleceu a ingestão de 400 a $500 \mu \mathrm{g} /$ semana como limite tolerável, o que corresponde à ingestão diária de $0,5 \mu \mathrm{g} / \mathrm{kg}$.

Desta forma este trabalho objetivou avaliar parâmetros qualitativos, como $\mathrm{pH}$, cor, capacidade de retenção de água, perdas de peso na cocção, força de cisalhamento, além da análise sensorial e a quantificação de resíduo de droga veterinária e metais pesados, na carne de cordeiros submetidos aos modelos de produção orgânico e convencional.

\section{Material e Método}

Este trabalho foi realizado na Faculdade de Ciências Agrárias e Veterinárias - FCAV, Unesp, Jaboti- 
cabal, SP. A fase experimental foi desenvolvida nas dependências do Setor de Ovinocultura pertencente ao Departamento de Zootecnia e a fase laboratorial em distintos laboratórios, dentre os quais: Laboratório de Nutrição Animal e Laboratório de Ruminantes pertencentes ao Departamento de Zootecnia da FCAV, Unesp (análises da composição bromatológica dos alimentos, de acordo com as normas analíticas do Instituto Adolfo Lutz) ${ }^{13}$, Laboratório de Tecnologia dos Produtos de Origem Animal (análises qualitativas da carne) e Laboratório de Biogeoquímica (análises de metais pesados) pertencentes ao Departamento de Tecnologia da FCAV, Unesp, e no Laboratório TASQA Serviços Analíticos, localizado em Paulínia, SP (análises de resíduo de ivermectina).

Foram utilizados 48 cordeiros Ile de France, machos não castrados, com peso corporal médio de 15 $\mathrm{kg}$, distribuídos em dois modelos de produção semiextensivo, o orgânico e o convencional, e abatidos aos $32 \mathrm{~kg}$ de peso corporal. Os cordeiros foram identificados individualmente com brincos na orelha. A pesagem e o monitoramento das infecções parasitárias, pelo método FAMACHA ${ }^{14}$. e pela contagem do número de ovos de nematódeos por grama de fezes (OPG), utilizando o método de McMaster modificado $^{15}$, foram realizados a cada 14 dias. A desverminação foi recomendada toda vez que a contagem estivesse acima de 500 OPG, sendo que no modelo convencional foi utilizado anti-helmíntico sintético, tendo como princípio ativo a ivermectina, e no modelo orgânico o medicamento homeopático Arsenicum album na potência $30 \mathrm{CH}$, fornecido três vezes por semana na água dos animais, na proporção de $0,3 \%$, pois os bebedouros nos piquetes tinham registro individual para abertura ou fechamento do fluxo de água, sendo permitido o controle do fornecimento. No concentrado dos animais do modelo orgânico foi utilizado ainda fitoterápico comercial constituído por alho (Allium sativum L.) e neem (Azadirachta indica), na proporção de $2 \%$ do concentrado.
Este trabalho foi desenvolvido a partir do $60^{\circ}$ dia de gestação das ovelhas até o abate dos cordeiros, compreendendo um período médio de 238 dias, correspondente aos 88 últimos dias de gestação, aos 60 dias da fase do nascimento ao desmame e aos 90 dias da fase do desmame ao abate. A partir do último terço da gestação as ovelhas foram colocadas na pastagem de tifton-85, permanecendo em áreas distintas conforme o modelo de produção, orgânico ou convencional.

As ovelhas receberam desde o terço final da gestação até o desmame dos cordeiros, dieta formulada com $13,7 \%$ de proteína bruta $(\mathrm{NRC})^{16}$, contendo $60 \%$ de cana-de-açúcar e $40 \%$ de concentrado, constituído por $44,1 \%$ de milho moído, $55,0 \%$ de farelo de soja, $0,25 \%$ de fosfato bicálcico e $0,65 \%$ de sal mineral, conforme composição bromatológica descrita: Orgânico - 53,38\% MS, 1,80\% MM, 17,26\% PB, 2,62\% EE, $15,60 \%$ FDN, $18,98 \%$ FDA e 2,39 Mcal EB/kg MS; Convencional - 54,32\% MS, 1,79\% MM, 17,56\% PB, 1,01\% EE, 17,66\% FDN, 22,51\% FDA e 2,37 Mcal EB/ $\mathrm{kg}$ MS. Os cordeiros foram aleitados pelas ovelhas até o desmame, aos $15 \mathrm{~kg}$ de peso corporal, e tiveram livre acesso ao creep feeding, recebendo suplementação alimentar formulada com $20,0 \%$ de proteína bruta $(\mathrm{NRC})^{16}$, contendo $60,0 \%$ de milho moído, 25,0\% de farelo de soja, $11,5 \%$ de farelo de trigo, $3,0 \%$ de fosfato bicálcico e $0,5 \%$ de sal mineral, conforme composição bromatológica descrita: Orgânico - 90,32\% MS, 5,39\% MM, 19,31\% PB, 4,32\% EE, 19,63\% FDN, 3,89\% FDA e 3,91 Mcal EB/kg MS; Convencional $90 \%$ MS, 5,45\% MM, 16,61\% PB, 3,03\% EE, 23,14\% FDN, 5,84,51\% FDA e 3,87 Mcal EB/kg MS.

$\mathrm{O}$ acesso ao concentrado para os cordeiros foi livre, com fornecimento médio diário de $200 \mathrm{~g} /$ cordeiro, com pesagens diárias das quantidades fornecidas e das sobras, para cálculo do consumo médio diário dos cordeiros.

Quando os cordeiros foram desmamados, já divididos em dois grupos (modelo orgânico e convencional) de 24 cordeiros cada, permaneceram na pastagem de 
tifton-85 e receberam dieta formulada com $18,0 \%$ de proteína bruta $(\mathrm{NRC})^{16}$, contendo $50 \%$ de cana-deaçúcar e $50 \%$ de concentrado, constituído por $36,0 \%$ de milho moído, $61,0 \%$ de farelo de soja, 2,6\% de fosfato bicálcico e $0,4 \%$ de sal mineral, conforme composição bromatológica descrita: Orgânico - 59,87\% MS, 3,49\% MM, 14,83\% PB, 3,23\% EE, 15,01\% FDN, 6,28\% FDA e 2,67 Mcal EB/ kg MS; Convencional $60,99 \%$ MS, 3,46\% MM, 15,78\% PB, 2,14\% EE, 17,25\% FDN, 7,64\% FDA e 2,62 Mcal EB/ kg MS.

Foi utilizado 1,6 ha de pastagem, com duas áreas de 0,8 ha cada, utilizando-se pastejo rotacionado, com período de ocupção de 7 sete dias e descanso de 45 dias $^{17}$. Cada área de 0,8 ha foi subdiviida em 8 oito piquetes de 0,1 ha, equipados com comedouro e bebedouro. A composição bromatológica do tifton- 85 durante o período experimental foi de $14,9 \%$ de proteína bruta; $66,9 \%$ de fibra em detergente neutro; $27,7 \%$ de fibra em detergente ácido e 8,3\% de lignina.

Para a produção de carne de cordeiro no modelo orgânico foram utilizados os princípios e fundamentos das diretrizes do Instituto Biodinâmico ${ }^{8}$, localizado em Botucatu, SP, o qual acompanhou o desenvolvimento desta pesquisa, sendo os grãos utilizados provenientes de unidades certificadas pelo referido Instituto.

O delineamento experimental foi o inteiramente casualizado, com dois tratame quatro24 repetições. As comparações dos contrastes entre médias dos tratamentos foram feitas pelo teste de Tukey a 5\% e as análises de variância conforme procedimentos do $\mathrm{SAS}^{18}$.

Os cordeiros foram abatidos ao atingirem $32 \mathrm{~kg}$ de peso corporal, após 16 horas de dieta sólida. A insensibilização foi realizada por eletronarcose de $220 \mathrm{~V}$ por 8 segundos, e em seguida seccionadas as veias jugulares e as artérias carótidas para a sangria, de acordo com procedimentos que caracterizam o abate humanitário ${ }^{19}$. Imediatamente após o abate, no músculo Longissimus dorsi foram determinados $\mathrm{pH}$, temperatura e cor. A leitura do $\mathrm{pH}$ foi feita com a utilização de eletrodo de penetração, a temperatura através de ter- mômetro digital e a cor através de colorímetro, o qual determina as coordenadas $\mathrm{L}^{*}, \mathrm{a}^{*} \mathrm{e} \mathrm{b}^{*}$, responsáveis pela luminosidade, teor de vermelho e teor de amarelo, respectivamente ${ }^{20}$. As carcaças permaneceram em câmara frigorífica a $4{ }^{\circ} \mathrm{C}$ por 24 horas, quando foram registrados novamente o $\mathrm{pH}$, a temperatura e a cor no músculo Longissimus dorsi.

Foram retiradas amostras do músculo Longissimus dorsi nas quais foram avaliadas a capacidade de retenção de água ${ }^{21}$, as perdas de peso na cocção, a força de cisalhamento $^{22}$ e a análise sensorial, utilizando-se no mínimo 30 provadores não-treinados, que avaliaram os atributos: sabor, maciez e impressão global23 .

Amostras do músculo Longissimus dorsi foram retiradas para determinação de resíduos de ivermecti$\mathrm{na}^{24}$, e dos metais pesados arsênio, cádmio e chumbo por espectrofotometria de absorção atômica ${ }^{25}$.

\section{Resultados}

A carne dos cordeiros do modelo orgânico teve maior teor de amarelo $(-0,99)$ que a dos cordeiros do modelo convencional $(-1,66)$, sendo que os demais parâmetros $\mathrm{L}^{*} \mathrm{e} \mathrm{a}^{\star}$ não foram afetados. A cor da carne dos cordeiros 24 horas após o abate, não foi influenciada $(\mathrm{P}>0,05)$ pelos tratamentos, com valores para $L^{\star}$ de 39,72; $\mathrm{a}^{\star}$ de 12,76 e b* de 1,05 (Tabela 1). A cor da gordura perirrenal não diferiu $(\mathrm{P}>0,05)$ entre tratamentos, com valores para $\mathrm{L}^{*}, \mathrm{a}^{*}$ e b* de 63,73; 5,76 e 5,22 (45 minutos após o abate) e de 73,93; 8,35 e 7,85 (24 horas após o abate), respectivamente (Tabela 2).

Com relação ao pH aos 45 minutos e 24 horas após o abate não houve diferença significativa entre os tratamentos $(P>0,05)$ com valores de 6,47 e 5,79 respectivamente, o mesmo ocorreu com a temperatura aos 45 minutos $\left(35,25^{\circ} \mathrm{C}\right)$ e 24 horas após o abate $(8,57$ $\left.{ }^{\circ} \mathrm{C}\right)$ (Tabela 3).

Os tratamentos não influenciaram $(\mathrm{P}>0,05)$ os teores de arsênio $(2,74 \mu \mathrm{g} / \mathrm{kg})$, cádmio $(0,48 \mathrm{~g} / \mathrm{kg})$ e chumbo $(0,04 \mathrm{~g} / \mathrm{kg})$ da carne (Tabela 4). Em relação 
Tabela 1 - Cor $\left(\mathrm{L}^{*}, \mathrm{a}^{\star} \mathrm{e} \mathrm{b}^{\star}\right)$ da carne de cordeiros submetidos aos modelos de produção orgânico e convencional - Jaboticabal - SP - 2009

\begin{tabular}{|c|c|c|c|c|c|}
\hline \multirow{2}{*}{ Parâmetro } & \multicolumn{2}{|c|}{ Modelo de produção } & \multirow{2}{*}{$\mathrm{F}$} & \multirow{2}{*}{$\operatorname{Pr}>F$} & \multirow{2}{*}{ CV (\%) } \\
\hline & Orgânico & Convencional & & & \\
\hline \multicolumn{6}{|c|}{45 minutos após o abate } \\
\hline $\mathrm{L}^{*}$ & 33,23 & 31,32 & 3,99 & 0,0690 & 5,57 \\
\hline$a^{*}$ & 11,37 & 10,82 & 0,54 & 0,4772 & 12,73 \\
\hline $\mathrm{b}^{*}$ & $-0,99^{a}$ & $-1,66^{\mathrm{b}}$ & 5,01 & 0,0445 & $-42,53$ \\
\hline \multicolumn{6}{|c|}{24 horas após o abate } \\
\hline $\mathrm{L}^{*}$ & 39,78 & 39,65 & 0,02 & 0,8983 & 4,71 \\
\hline$a^{*}$ & 12,82 & 12,70 & 0,03 & 0,8645 & 10,17 \\
\hline$b^{*}$ & 1,06 & 1,03 & 0,00 & 0,9616 & 105,45 \\
\hline
\end{tabular}

F -Valor de F; Pr > F -Probabilidade; CV - Coeficiente de variação; $\mathrm{L}^{*}$ - luminosidade; $\mathrm{a}^{*}$ - teor de vermelho; $\mathrm{b}^{*}$ - teor de amarelo; ${ }^{\mathrm{a}, \mathrm{b}}$ Médias seguidas de letras diferentes na mesma linha diferem pelo teste de Tukey a $5 \%$ de probabilidade.

Tabela 2 - Cor $\left(\mathrm{L}^{*}, \mathrm{a}^{*} \mathrm{e} \mathrm{b}^{\star}\right)$ da gordura perirrenal de cordeiros submetidos aos modelos de produção orgânico e convencional em experimento desenvolvido em Jaboticabal, SP, ano de 2009

\begin{tabular}{ccccccc}
\hline \multirow{2}{*}{ Parâmetro } & \multicolumn{2}{c}{ Modelo de produção } & \multirow{2}{*}{$\mathrm{F}$} & \multirow{2}{*}{ Pr $>\mathrm{F}$} & \multirow{2}{*}{$\mathrm{CV}(\%)$} \\
\cline { 2 - 3 } & \multicolumn{2}{c}{ Orgânico } & Convencional & & \\
\hline \multicolumn{7}{c}{45 minutos após o abate } \\
\hline $\mathrm{L}^{*}$ & 64,04 & 63,42 & 0,07 & 0,7907 & 6,70 \\
$\mathrm{a}^{*}$ & 4,95 & 6,56 & 2,56 & 0,1357 & 32,82 \\
$\mathrm{~b}^{*}$ & 5,22 & 5,21 & 0,00 & 0,9902 & 46,30 \\
\hline \multicolumn{7}{c}{24 horas após o abate } \\
\hline $\mathrm{L}^{*}$ & $76,24^{\mathrm{a}}$ & $71,61^{\mathrm{b}}$ & 9,23 & 0,0103 & 3,86 \\
$\mathrm{a}^{*}$ & $6,66^{\mathrm{b}}$ & $10,03^{\mathrm{a}}$ & 12,99 & 0,0036 & 20,93 \\
$\mathrm{~b}^{*}$ & 7,58 & 8,11 & 2,06 & 0,1766 & 8,75 \\
\hline
\end{tabular}

F -Valor de F; Pr > F -Probabilidade; CV - Coeficiente de variação; $\mathrm{L}^{*}$ - luminosidade; $\mathrm{a}^{*}$ - teor de vermelho; $\mathrm{b}^{*}$ - teor de amarelo; ${ }^{\mathrm{a}, \mathrm{b}}$ Médias seguidas de letras diferentes na mesma linha diferem pelo teste de Tukey a $5 \%$ de probabilidade.

Tabela 3 - Medidas de $\mathrm{pH}$ e temperatura $\left({ }^{\circ} \mathrm{C}\right)$ da carne de cordeiros submetidos aos modelos de produção orgânico e convencional em experimento desenvolvido em Jaboticabal, SP, ano de 2009

\begin{tabular}{|c|c|c|c|c|c|}
\hline \multirow{2}{*}{ Parâmetro } & \multicolumn{2}{|c|}{ Modelo de produção } & \multirow[b]{2}{*}{$\mathrm{F}$} & \multirow[b]{2}{*}{$\operatorname{Pr}>F$} & \multirow[b]{2}{*}{ CV (\%) } \\
\hline & Orgânico & Convencional & & & \\
\hline \multicolumn{6}{|c|}{45 minutos após o abate } \\
\hline $\mathrm{pH}$ & 6,51 & 6,43 & 0,45 & 0,5143 & 3,50 \\
\hline Temperatura $\left({ }^{\circ} \mathrm{C}\right)$ & 35,86 & 34,64 & 0,78 & 0,3950 & 7,30 \\
\hline \multicolumn{6}{|c|}{24 horas após o abate } \\
\hline $\mathrm{pH}$ & 5,76 & 5,82 & 0,15 & 0,7056 & 5,60 \\
\hline Temperatura $\left({ }^{\circ} \mathrm{C}\right)$ & 7,97 & 9,17 & 1,16 & 0,3036 & 24,37 \\
\hline
\end{tabular}

F -Valor de F; Pr > F -Probabilidade; CV - Coeficiente de variação.

Tabela 4 - Teores de arsênio $(\mu \mathrm{g} / \mathrm{kg})$, cádmio $(\mathrm{g} / \mathrm{kg})$ e chumbo $(\mathrm{g} / \mathrm{kg})$ do músculo Longissimus dorsi de cordeiros submetidos aos modelos de produção orgânico e convencional em experimento desenvolvido em Jaboticabal, SP, ano de 2009

\begin{tabular}{ccccccc}
\hline \multirow{2}{*}{ Teor } & \multicolumn{2}{c}{ Modelo de produção } & \multirow{2}{*}{ F } & Pr $>$ F & CV $(\%)$ \\
\cline { 2 - 3 } & Orgânico & Convencional & & 0,61 & 0,4512 & 47,71 \\
Arsênio $(\mu \mathrm{g} / \mathrm{kg})$ & 2,46 & 3,02 & & 4,54 & 0,0529 & 46,03 \\
Cádmio $(\mathrm{g} / \mathrm{kg})$ & 0,35 & 0,60 & & 3,86 & 0,0713 & 53,27 \\
Chumbo $(\mathrm{g} / \mathrm{kg})$ & 0,03 & 0,05 & &
\end{tabular}

F -Valor de F; Pr > F -Probabilidade; CV - Coeficiente de variação.

ao resíduo de ivermectina na carne dos cordeiros provenientes dos modelos de produção orgânico e convencional, o limite de quantificação do método de $2,5 \mu \mathrm{g} / \mathrm{kg}$ de carne não foi atingido, podendo-se con- 
siderar inexistência do princípio ativo nas amostras. Considerando que os cordeiros do modelo orgânico não receberam doses de anti-helmíntico, e que os do modelo convencional receberam tais doses, respeitando o período de carência de 28 dias para o abate dos cordeiros, pode-se comprovar não haver efeito residual do princípio ativo no produto, conforme salvaguardado pelo fabricante.

Os dados referentes aos parâmetros qualitativos da carne de cordeiros submetidos aos modelos de produção orgânico e convencional situam-se na tabela 5. As perdas de peso na cocção foram influenciadas $(\mathrm{P}<0,05)$ pelos tratamentos, sendo que na carne dos cordeiros do mode- lo orgânico, as perdas foram menores (36,85\%) quando comparadas às perdas no modelo convencional (44,23\%).

Para os modelos orgânico e convencional os valores de perdas de peso na cocção foram de 13,41 e 24,54\%, respectivamente. A capacidade de retenção de água $(56,27 \%)$ e a força de cisalhamento $\left(2,66 \mathrm{kgf} / \mathrm{cm}^{2}\right)$ não foram afetadas $(\mathrm{P}>0,05)$ pelos modelos.

Em relação à análise sensorial, observou-se que na carne dos cordeiros criados no modelo orgânico, tanto as notas para maciez $(6,73)$ quanto para aceitação global $(6,70)$ foram menores $(\mathrm{P}>0,05)$ quando comparadas às dos cordeiros do modelo convencional, cujas notas foram 7,43 e 7,47, respectivamente (Tabela 5).

Tabela 5 - Parâmetros qualitativos e características sensoriais da carne proveniente do músculo Longissimus dorsi de cordeiros submetidos aos modelos de produção orgânico e convencional em experimento desenvolvido em Jaboticabal, SP, ano de 2009

\begin{tabular}{|c|c|c|c|c|c|}
\hline \multirow{2}{*}{ Parâmetro } & \multicolumn{2}{|c|}{ Modelo de produção } & \multirow{2}{*}{$\mathrm{F}$} & \multirow{2}{*}{$\operatorname{Pr}>F$} & \multirow{2}{*}{$\mathrm{CV}(\%)$} \\
\hline & Orgânico & Convencional & & & \\
\hline CRA (\%) & 57,26 & 55,27 & 0,95 & 0,3477 & 7,03 \\
\hline $\mathrm{PC}(\%)$ & $36,85^{\mathrm{b}}$ & $44,23^{\mathrm{a}}$ & 17,62 & 0,0010 & 8,33 \\
\hline $\mathrm{FC}\left(\mathrm{kgf} / \mathrm{cm}^{2}\right)$ & 2,57 & 2,74 & 0,13 & 0,7232 & 33,86 \\
\hline Sabor & 6,67 & 7,40 & 3,66 & 0,0607 & 21,11 \\
\hline Maciez & $6,73^{b}$ & $7,43^{\mathrm{a}}$ & 4,67 & 0,0348 & 17,71 \\
\hline Aceitação global & $6,70^{\mathrm{b}}$ & $7,47^{\mathrm{a}}$ & 4,58 & 0,0367 & 19,60 \\
\hline
\end{tabular}

F -Valor de F; Pr > F -Probabilidade; CV - Coeficiente de variação; CRA - capacidade de retenção de água; PC - perdas de peso na cocção; FC - força de cisalhamento; ${ }^{\text {a,b }}$ Médias seguidas de letras diferentes na mesma linha diferem pelo teste de Tukey a $5 \%$ de probabilidade.

\section{Discussão}

Em ovinos são descritos valores de 31,36 a 38,0 para $L^{\star}$, de 12,27 a 18,01 para $a^{*}$ e de 3,34 a 5,65 para ${ }^{* 26}$. No presente experimento, os valores de $\mathrm{L}^{*}$, avaliados $45 \mathrm{mi}-$ nutos após o abate, estão contidos neste intervalo, entretanto, os valores avaliados 24 horas após o abate, foram superiores, com tendência da coloração da carne para o branco. Souza et al. ${ }^{27}$, ao avaliarem a cor da carne proveniente do músculo Longissimus dorsi de cordeiros abatidos aos $25 \mathrm{~kg}$ de peso corporal, encontraram valores de $L^{*}$ de 33,64. Comumente são observados valores de $L^{*}$ mais altos nas carnes de cordeiros, pois estes apresentam maior quantidade de água e menor de gordura, quando cmparados àa animais mais velhos, os quais modificam a composição centesimal da carne, prevalecendo maior deposição de gordura e em proporção menor, a quanti- dade de água no tecido muscular, resultando em carne com $L^{\star}$ menos elevada, ou seja, mais escura ${ }^{28}$.

Os valores de $\mathrm{a}^{*}$, avaliados 24 horas após o abate, enquadraram-se nestes intervalos, porém na avaliação realizada 45 minutos após o abate, foram inferiores ao intervalo reportado. Já para o parâmetro $b^{\star}$ foram observados valores inferiores, com tendência à coloração azul. Os valores encontrados de $\mathrm{pH}$ podem ser considerados adequados, sendo importante ressaltar que a constatação de valores normais de queda do $\mathrm{p}$ da carne, indica que outros parâmetros qualitativos, como capacidade de retenção de água, cor e maciez serão apropriados ${ }^{28}$.

Com relação às perdas de peso na cocção, em experimento para avaliar a carne de cordeiros Merino proveniente do músculo Longissimus dorsi nos modelos orgânico e convencional, Morbidini et al. ${ }^{29}$ observaram 
diferenças $(P<0,05)$ significativas entre os tratamentos, com valores de 13,41 e $24,54 \%$ para os modelos orgânico e convencional, respectivamente. Da mesma forma, também observaram diferenças $(\mathrm{P}<0,05)$ para a força de cisalhamento da carne de cordeiros criados no modelo orgânico $\left(5,64 \mathrm{kgf} / \mathrm{cm}^{2}\right)$ em relação à dos criados no modelo convencional $\left(4,16 \mathrm{kgf} / \mathrm{cm}^{2}\right)$.

Metais como arsênio, cádmio e chumbo podem ser considerados contaminantes inorgânicos, cujos limites de tolerância ou limite máximo de resíduo (LMR) são estabelecidos pela OMS. De acordo com o Programa Nacional de Controle de Resíduos em Carne (PNCRC) do BRASIL $^{5}$ os valores permitidos de cádmio e chumbo para carne bovina são respectivamente de 0,001 e 0,002 $\mathrm{g} / \mathrm{kg}$ de carne, enquanto para o arsênio não há ainda limite estabelecido para carne, apenas sendo citado $0,0027 \mathrm{~g} / \mathrm{kg}$ como limite para teor nos rins ou fígado.

Os valores obtidos nesta pesquisa serão comparados com aqueles para carne bovina, considerando que o PNCRC ainda não estipulou valores para a espécie ovina. Sendo assim, os valores de cádmio $(0,48 \mathrm{~g} / \mathrm{kg}$ de carne) e chumbo (0,04 g/kg de carne) nos modelos estudados foram muito superiores ao LMR permitido, podendo as amostras terem sido contaminadas no próprio laboratório durante a execução das análises.

Em relação ao resíduo de ivermectina na carne dos cordeiros provenientes dos modelos de produção orgânico e convencional, o limite de quantificação do método de $2,5 \mu \mathrm{g} / \mathrm{kg}$ de carne não foi atingido, podendo-se considerar inexistência do princípio ativo nas amostras. Considerando que os cordeiros do modelo orgânico não receberam doses de anti-helmíntico, e que os do modelo convencional receberam tais doses, respeitando o período de carência de 28 dias para o abate dos cordeiros, pôde-se comprovar não haver efeito residual do princípio ativo no produto, conforme salvaguardado pelo fabricante. De acordo com o PNCRC doBRASIL ${ }^{30}$ o LMR para resíduo de ivermectina em músculo bovino é de $100 \mu \mathrm{g} / \mathrm{kg}$ e neste caso valores inferiores aos $2,5 \mu \mathrm{g} / \mathrm{kg}$ de carne sugerem carne adequada para o consumo.
$\mathrm{Na}$ análise sensorial a nota dos provadores foi ndicativao da qualidade da carne ovina, pois os valores foram superiores a 6,67. Zeola et al. ${ }^{31}$, ao avaliarem sensorialmente a carne de cordeiros Morada Nova, abatidos ao $25 \mathrm{~kg}$ e criados em um modelo convencional, observaram notas de 7,5; 7,5 e 7,2 para os atributos sabor, maciez e impressão global, respectivamente. Sales et al. ${ }^{32}$, estudando os atributos sensoriais da carne de cordeiros submetidos ao modelo convencional de produção, abatidos aos $32 \mathrm{~kg}$, constataram notas de 6,6 para o sabor, 7,4 para a maciez e 6,8 para a impressão global.

Ao avaliarem a qualidade sensorial da carne de novilhos proveniente do músculo Longissimus dorsi criados nos modelos orgânico e convencional, Walshe et al. ${ }^{33}$ não observaram diferenças $(P>0,05)$ nos atributos odor, sabor e textura das carnes .

\section{Conclusões}

Carne de cordeiros submetidos aos modelos de produção orgânico e convencional apresentaram parâmetros qualitativos similares, com exceção das perdas de peso na cocção, as quais foram maiores para as carnes produzidas no modelo convencional, e dos parâmetros maciez e aceitação global da análise sensorial, que receberam notas maiores para as carnes produzidas no modelo convencional.

Traços do princípio ativo ivermectina, em ambos os modelos estudados, não foram detectados, demostrando a inocuidade da carne ovina frente ao mercado consumidor.

\section{Agradecimentos}

À Fundação de Amparo à Pesquisa do Estado de São Paulo (FAPESP), pela concessão do auxílio financeiro e da bolsa de estudos, à Usina Santo Antônio S/A pelo fornecimento da cana-de-açúcar produzida no modelo orgânico e ao Instituto Biodinâmico (IBD) pelo fornecimento das diretrizes para criação de animais domésticos no modelo orgânico de produção. 


\section{Referências}

1. COMERÓN, E. A.; ANDREO, N. A. Produção, industrialização e comercialização do leite orgânico na Argentina. In: SIMPÓSIO SOBRE A SUSTENTABILIDADE DA PECUÁRIA LEITEIRA NO BRASIL, 2., 2000, Goiânia. Anais... Juiz de Fora: Embrapa Gado de Leite, 2000. p. 146-174.

2. BELLAVER, C. Produção animal e qualidade de vida nas sociedades em transição. In: REUNIÃO ANUAL DA SOCIEDADE BRASILEIRA DE ZOOTECNIA, 39., 2002, Recife. Anais... Recife: Sociedade Brasileira de Zootecnia, 2002. p. 317-331.

3.SANTOS, G. C.; MONTEIRO, M. Modelo orgânico de produção de alimentos. Alimentos e Nutrição, v. 15, n. 1, p. 73-86, 2004.

4. ANGOOD, K. M.; WOOD, J. D.; NUTE, G. R. A comparison of organic and conventionally-produced lamb purchased from three major UK supermarkets: price, eating quality and fatty acid composition. Meat Science, v. 78, p. 176-184, 2008.

5. BRASIL. Ministério da Agricultura, Pecuária e Abastecimento. Portaria $\mathrm{n}^{\circ} 50$, de 20 de fevereiro de 2006. Diário Oficial União, Poder Executivo, Brasília, DF, 03 mar. 2006. Sec. 1, p.15.

6. BARBOSA FILHO, J. A. D.; SILVA, J. O. Abate humanitário: ponto fundamental do bem-estar animal. Revista Nacional Carne, n. 328, p. 36-44, 2004.

7. BRASIL. Ministério da agricultura e do abastecimento. Instrução Normativa $\mathrm{n}^{\circ} 7$, de 17 de maio de 1999. Diário Oficial República Federativa do Brasil, Brasília, maio 1999. Sec. 1, p. 11-14.

8. INSTITUTO BIODINÂMICO. (IBD). Diretrizes para o padrão de qualidade “Orgânico Instituto Biodinâmico”. 13 ed. Botucatu: IBD, 2006. 87 p.

9. STRINGHETA, P. C.; MUNIZ, J. N. Alimentos orgânicos produção, tecnologia e certificação. Viçosa:UFV, 2003. 452 p.

10. OLIVO, C. J. Sustentabilidade de condomínios rurais formados por pequenos agricultores familiares: análise e proposta de modelo de gestão. 2000. $257 \mathrm{f}$. Tese (Doutorado em Engenharia de Produção) - Universidade Federal de Santa Catarina, Florianópolis, 2000.

11.PORTUGAL, A. V. Modelos de produção de alimentos de origem animal no futuro. Revista Portuguesa de Ciências Veterinárias, v. 97, n. 542, p. 63-70, 2002.

12.DUARTE, K. M. R.; SILVA, F. M. S. M.; MEIRELLES, C. F. Resíduos de anabolizantes na produção animal: importância e métodos de detecção. Ciência Rural, Santa Maria, v. 32, n. 34, p. 731-737, 2002.

13.INSTITUTO ADOLFO LUTZ. Métodos físico-químicos para análise de alimentos. In:_. Normas Analíticas do Instituto Adolfo Lutz. 4. ed. São Paulo: IMESP, 2008. 1020 p.

14. MOLENTO, M. B.; TASCA, C.; GALLO, A.; FERREIRA, M.; BONONI, R.; STECCA, E. Método Famacha como parâmetro clínico individual de infecção por haemonchus contortus em pequenos ruminantes. Ciência Rural, v. 34, n. 4, p. 1138-1145, 2004.

15.SLOSS, M. W.; ZAJAC, A. M.; KEMP, R. L. Parasitologia clínica veterinária. São Paulo: Manole, 1999. 198 p.

16.NCR. NATIONAL RESEARCH COUNCIL. Nutrient requirements of sheep. New York: National Academy Press, $1985.99 \mathrm{p}$.

17.SILVA SOBRINHO, A. G. Produção de cordeiros em pastagem. In: SIMPÓSIO MINEIRO DE OVINOCULTURA, 1., 2001, Lavras. Anais... Lavras: UFLA, 2001. p. 63-97.
18.SAS. STATISTICAL ANALISYS SYSTEM. SAS user's guide: statistics. Version 6.12. 4. ed. Cary: SAS Institute, 1996. v. 1/2.

19. MONTEIRO JÚNIOR, L. A. Avaliação das técnicas de insensibilização de ovinos abatidos na região de Botucatu. 2000. 166 f. Dissertação (Mestrado em Medicina Veterinária) Faculdade de Medicina Veterinária e Zootecnia, Universidade Estadual Paulista, Botucatu, 2000.

20.MILTENBURG, G. A. J.; WENSING, T.; SMULDERS, F. J. M.; BREUKINK, H. J. Relationship between blood hemoglobin, plasma and tissue iron, muscle heme pigment, and carcass color of veal. Journal of Animal Science, v. 70, n. 9, p. 2766$2772,1992$.

21.SILVA SOBRINHO, A. G. Body composition and characteristics of carcass from lambs of different genotypes and ages at slaughter. 1999. 54 p. Tese (Post Doctorate in Sheep Meat Production) - Massey University, Palmerston North, 1999.

22. OSÓRIO, J. C. S.; OSÓRIO, M. T. M.; JARDIM, P. O. C.; PIMENTEL, M.; POUEY, J. L.; LUDER, W. E.; CARDELLINO, R. A.; OLIVEIRA, N. M.; BORBA, M. F.; MOTTA, L.; ESTEVES, R. Métodos para avaliação da produção de carne ovina: "in vivo", na carcaça e na carne. Pelotas: UFPEL, 1998. $107 \mathrm{p}$.

23. MORAES, M. A. C. Métodos para avaliação sensorial dos alimentos. Campinas: Editora da UNICAMP, 1993. 93 p.

24. TWAY, P. C.; WOOD, J. S.; DOWNING, G. V. Determination of ivermectin in cattle and sheep tissues using high-performance liquid chromatography with fluorescence detection. Journal of Agricultural Food Chemistry, v. 29, n. 5, p. 1059-1063, 1981.

25. OFFICE OF SOLID WASTE AND EMERGENCY RESPONSE. US Enviroment Protection Agency. Test methods for evaluating solid wastes. (EPA SW 846) method 3050. Washington: Office of Solid Waste and Emergency Response, 1986. 153 p.

26.FARIA, P. B.; BRESSAN, M. C.; ODA, S. H. I. Características de $\mathrm{pH}$ e cor (CIELAB) de carne de capivaras (Hydrochaeris hydrochaeris L. 1766) nas primeiras $24 \mathrm{~h}$ post mortem. In: SIMPÓSIO LATINO AMERICANO DE CIÊNCIA DE ALIMENTOS, 4., 2001, Campinas. Anais... Campinas, 2001. p. 157.

27.SOUZA, X. R.; BRESSAN, M. C.; PÉREZ, J. R. O.; FARIA, P. B.; VIEIRA, J. O.; KABEYA, D. M. Efeitos do grupo genético, sexo e peso ao abate sobre as propriedades físico-químicas da carne de cordeiros em crescimento. Ciência e Tecnologia de Alimentos, v. 24, n. 4, p. 543-549, 2004.

28.ZEOLA, N. M. B. L. Influência da alimentação nas características quantitativas da carcaça e qualitativas da carne de cordeiros Morada Nova. 2002. 65 f. Dissertação (Mestrado em Zootecnia) - Faculdade de Ciências Agrárias e Veterinárias, Universidade Estadual Paulista, Jaboticabal, 2002.

29.MORBIDINI, L.; SARTI, D. .; POLIDORI, P.; VALIGI, A. Carcass, meat and fat quality in italian Merino derived lambs obtained with organic farming systems. In: RECENT PROGRESS IN ANIMAL PRODUCTION SCIENCE, 1., 1999, Piacenza. Anais... Piacenza: ASPA, 1999. p. 598-600.

30.BRASIL. Ministério da agricultura, pecuária e abastecimento. Instrução Normativa $\mathrm{n}^{\circ} 10$, de 14 de abril de 2008. Diário Oficial União, Brasília, 14 abr. 2008. Sec. I, p. 29.

31.ZEOLA, N. M. B. L.; SOUZA, P. A.; SOUZA, H. B. A.; SILVA SOBRINHO, A. G. Características sensoriais da carne de cordeiros maturada e injetada com cloreto de cálcio. Archivos de Zootecnia, v. 59, n. 228, p. 539-548, 2010. 
32. SALES, R. O.; SILVA SOBRINHO, A. G.; MANZI, G. M.; ZEOLA N. M. B. L.; ENDO, V. Características sensoriais do músculo Longissimus dorsi de cordeiros alimentados com dieta contendo grãos de girassol e vitamina $\mathrm{E}$ em diferentes dias de maturacão In: REUNIÃO ANUAL DA SOCIEDADE BRASILEIRA DE ZOOTECNIA, 47., 2010, Salvador. Anais... Salvador: SBZ, 2010.
33. WALSHE, B. E.; SHEEHAN, E. M.; DELAHUNTY, C. M.; MORRISSEY, P. A.; KERRY, J. P. Composition, sensory and shelf life stability analyses of Longissimus dorsi muscle from steers reared under organic and conventional production systems. Meat Science, v. 73, n. 2, p. 319-325, 2006. 